Bridgewater State University

2014

\title{
Seasonal Patterns of Microhabitat Selection by a Sub-tropical Whip Spider, Phrynus longipes, in the Luquillo Experimental Forest, Puerto Rico
}

Caroline A. Curtis

Christopher P. Bloch

Bridgewater State University, cbloch@bridgew.edu

Follow this and additional works at: http://vc.bridgew.edu/biol_fac

Part of the Biology Commons, and the Entomology Commons

\section{Virtual Commons Citation}

Curtis, Caroline A. and Bloch, Christopher P. (2014). Seasonal Patterns of Microhabitat Selection by a Sub-tropical Whip Spider, Phrynus longipes, in the Luquillo Experimental Forest, Puerto Rico. In Biological Sciences Faculty Publications. Paper 38.

Available at: http://vc.bridgew.edu/biol_fac/38 


\title{
SHORT COMMUNICATION
}

\section{Seasonal patterns of microhabitat selection by a sub-tropical whip spider, Phrynus longipes, in the Luquillo Experimental Forest, Puerto Rico}

\author{
Caroline A. Curtis ${ }^{1}$ and Christopher P. Bloch ${ }^{2}$ : ${ }^{1}$ Graduate Program in Organismic and Evolutionary Biology, University \\ of Massachusetts Amherst, Amherst, Massachusetts 01003 USA. E-mail: cacurtis@cns.umass.edu; ${ }^{2}$ Department of \\ Biological Sciences, Bridgewater State University, Bridgewater, Massachusetts 02325 USA
}

\begin{abstract}
Phrynus longipes (Pocock 1894) is a top predator among arboreal invertebrates in the Luquillo Mountains of Puerto Rico, but many aspects of its ecology remain poorly understood. We sampled four of the most abundant tree species in the Luquillo Mountains during the dry and wet seasons of 2008 to evaluate microhabitat preferences of this species. In the dry season, P. longipes occurred significantly less frequently on a palm, Prestoea acuminata var. montana (Arecaceae), than the other tree species. Carapace length and the diameter of the tree on which an individual was found were positively correlated, suggesting competition for substrates. Microhabitat selection shifted in the wet season. Individuals occurred as frequently on $P$. acuminata as on any other species. The seasonal shift in substrate use could result from altered distribution or abundance of prey, an ontogenetic shift in substrate preference or greater competition arising from an increased abundance of $P$. longipes.
\end{abstract}

Keywords: Amblypygi, resource availability, competition, fitness, arboreal predators

Habitat selection contributes to individual fitness by affecting the ability to acquire resources, survive and reproduce (Rosenzweig 1981; Huey 1991). Furthermore, intra- and interspecific competition influence the ability of individuals to occupy optimal habitats (Whitham 1980; Stamps 1991). Habitat selection is likely to be affected by temporal changes in food availability, reproductive activity and the emergence of young, all of which occur seasonally (Wolda 1978). Therefore, a comprehensive understanding of habitat selection requires comparisons among seasons.

Whip spiders (Amblypygi) are nocturnal ambush predators that use vertical substrates, such as trees or rocks, for hunting and nearby crevices as mating or retreat sites. Adults of many species defend a small home range near the structure they employ for hunting (Weygoldt 2000). Patterns of habitat use are poorly known for most amblypygid species, but some factors associated with amblypygids that inhabit tropical forests have been identified. In the central Amazon Basin, Heterophrynus longicornis (Butler 1873) occurs most often on large trees with buttressed roots (Dias \& Machado 2007). In contrast, Porto \& Peixoto (2013) found that individuals were more likely to maintain their territory on a tree if a burrow was present at its base, regardless of tree size. The presence of termite nests at a tree base is another indicator of higher $H$. longicornis abundance (Carvalho et al. 2012). In Costa Rica Phrynus parvulus Pocock 1902 selects habitats based on tree surface area, the presence of buttresses and moss cover (Hebets 2002). Large trees with buttresses might be preferable if they provide high prey density in the deep leaf litter between roots (Heyer \& Berven 1973), or areas for mating or retreat sites.

Phrynus longipes (Pocock 1894) inhabits caves and forests on Hispaniola, Puerto Rico and the Virgin Islands (Quintero 1981), but relatively little is known about its ecology or behavior. A previous study of $P$. longipes in the Luquillo Mountains of northeastern Puerto Rico found individuals most often on the sierra palm, Prestoea acuminata var. montana (Arecaceae) (Bloch \& Weiss 2002). This is unusual compared to the habits of other whip spiders, as $P$. acuminata has a relatively small diameter compared to other trees in this forest and lacks buttresses. Two explanations could account for this unexpected pattern of habitat use. First, neither the sampling methodology nor the statistical analyses of Bloch \& Weiss (2002) explicitly accounted for tree species abundance, so $P$. longipes may have appeared to prefer $P$. acuminata simply because it was the most abundant substrate within the sampling plots. Second, the extensive anthropogenic and natural disturbance history of northeastern Puerto Rico might contribute to unique habitat characteristics and population dynamics. Until the 1930s, much of the land below $600 \mathrm{~m}$ was used for farming, logging and coffee cultivation (Thompson et al. 2002). In addition, hurricanes of moderate to high intensity hit the forest every 50-60 years on average, and storms of lesser intensity occur more frequently (Scatena \& Larson 1991). This disturbance regime would have necessitated adaptation by organisms to a heterogeneous, frequently changing environment, and could have affected patterns of habitat use.

This study evaluated whether $P$. longipes in the Luquillo Mountains actually selects substrates differently from other species of forestdwelling whip spider, or if the unusual pattern of habitat use observed by Bloch \& Weiss (2002) emerged simply because of a sampling bias. We compared use of $P$. acuminata to use of three other abundant trees in the Luquillo Mountains to determine whether P. acuminata was occupied more than expected by chance or was simply used in proportion to abundance. We also compared substrate use between dry and wet seasons to assess the effects of seasonality.

The Luquillo Experimental Forest (LEF) is an 11,300-ha reserve in the Luquillo Mountains of northeastern Puerto Rico, and is a site in the National Science Foundation's Long-Term Ecological Research Network (Hobbie et al. 2003). This study was conducted near the El Verde Field Station $\left(18^{\circ} 19^{\prime} 16.83^{\prime \prime} \mathrm{N}, 65^{\circ} 49^{\prime} 10.13^{\prime \prime} \mathrm{W}\right)$, in the northwestern region of the LEF, where elevation ranges from approximately 300 to $400 \mathrm{~m}$. Total annual precipitation at the El Verde Field Station averages $335 \mathrm{~cm} \mathrm{year}^{-1}$ (Heartsill-Scalley et al. 2007). Precipitation is mildly seasonal, with a relatively dry period from January to April (McDowell \& Estrada Pinto 1988). For 1975-1989, average monthly precipitation for the dry (January-April) and wet (May-December) seasons was approximately $22 \mathrm{~cm}$ and $35 \mathrm{~cm}$, respectively.

To determine the most dominant tree species in the area we sampled based on basal area (Thompson et al. 2002). From these common species, we selected four of the most abundant within our sampling area, each of which has a distinct root system. Prestoea 
Table 1.-Data for each of the two sampling periods are presented. The number $(n)$ of each tree species (Cs, C. schreberiana; Mb, M. bidentata; Pa, Prestoea acuminata; Sb, Sloanea berteriana) sampled, DBH for each of the four species and two seasons are included, as well as values combined for both sampling periods. The number of adult and juvenile $P$. longipes recorded on each species is also listed by tree species and season.

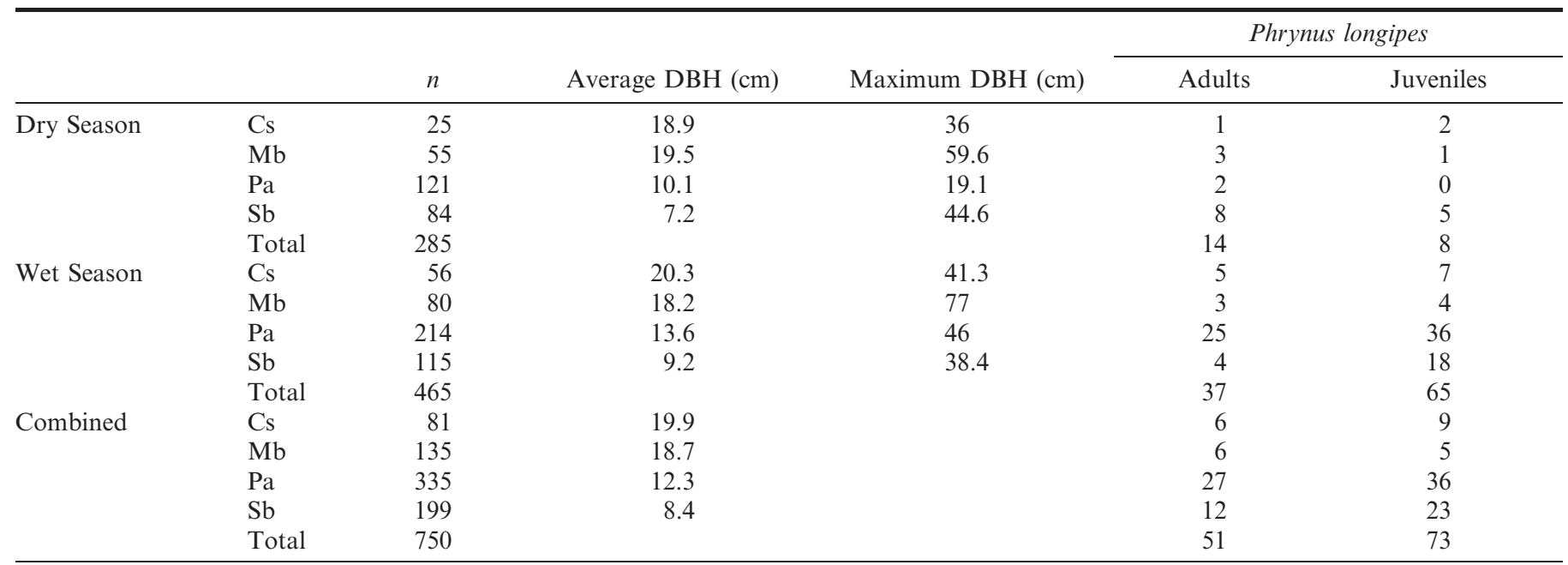

acuminata has a tightly packed system of prop roots, Cecropia schreberiana (Urticaceae) has widely spaced branching roots that angle off from the main stem, Sloanea berteriana (Elaeocarpaceae) develops buttresses as it grows, and Manilkara bidentata (Sapotaceae) has a straight trunk devoid of buttresses (Thompson et al. 2002).

Surveys were conducted in March 2008 (dry season) and from June to August 2008 (wet season). Sampling was conducted by two researchers and occurred between 20:00 and 02:00. As many trees as possible of each target species were found, and each was visually inspected up to a height of $2 \mathrm{~m}$, including all visible crevices, buttresses, and exposed roots. Total body length (TBL, the length of the abdomen and carapace) of each whip spider was measured using dial calipers (Table 1). Diameter at breast height (DBH) was measured using a diameter tape for all trees, regardless of presence or absence of whip spiders (Table 1).

Currently, there is no documentation of the size at which $P$. longipes becomes sexually mature. A congener, Phrynus marginemaculatus Koch 1840, is sexually mature when it has reached approximately half of its average adult size (Weygoldt 2000). Typical adult size of $P$. longipes is roughly $35 \mathrm{~mm}$ (Weygoldt 2000), so individuals were considered adults if TBL $\geq 18 \mathrm{~mm}$. All remaining individuals were considered juveniles. Although $18 \mathrm{~mm}$ is an arbitrary threshold, changing this value by a few $\mathrm{mm}$ did not substantively alter the results.

Chi-square contingency table analyses were used to test the null hypothesis that $P$. longipes occupied tree species randomly (i.e., in proportion to abundance). If there was a significant result, standardized residuals were examined to determine which species contributed most to the overall significant result. If a standardized residual exceeded two standard deviations (i.e., $-2.0>\mathrm{z}>2.0$ ), the associated count was considered to be significantly different from the expected.

Pearson's Product-moment Correlation Coefficient was used to test for an association between TBL of P. longipes and the DBH of trees on which individuals were found. For each season, analyses were conducted for all individuals, as well as for adults and juveniles separately. Further analyses assessed the relationship between TBL and DBH separately for each tree species.

Microhabitat selection by $P$. longipes was non-random in the dry season $\left(\chi^{2}=14.24, d f=3, P=0.003\right.$; Fig. 1a). Standardized residuals indicated that whip spiders were observed more frequently than expected on $S$. berteriana $(z=2.61)$ and less frequently than expected on $P$. acuminata $(z=-2.38)$. TBL of $P$. longipes was significantly and positively correlated with the DBH of trees on which it was found ( $r=0.68, P=0.001, n=22)$ when all individuals were included in the analysis and for adults only $(r=0.59, P=0.026, n=$ 14). Furthermore, the significant positive correlation between TBL of individuals and the DBH of $S$. berteriana on which they were found ( $r=0.72, P=0.005, n=13)$ suggests that, as occurs in other amblypygid species, larger individuals were selecting and defending territories on larger trees. However, for the remaining tree species, or when only juveniles on all trees were considered, TBL was not significantly correlated with DBH, suggesting that some individuals were unable to acquire or defend territory on the preferred trees. This may also correspond to the relatively small size range observed for the other tree species, especially $P$. acuminata, which rarely exceeded $20 \mathrm{~cm} \mathrm{DBH}$.

In the wet season, substrate use was non-random among the four tree species $\left(\chi^{2}=11.01, d f=3, P=0.012\right.$; Fig. $\left.1 \mathrm{~b}\right)$. Whip spiders were observed less frequently than expected on $M$. bidentata, the species with the simplest above-ground component of the root system and the least surface area $(z=-2.21)$. This was also true if the analysis was restricted to juvenile whip spiders $(z=-2.14)$. Other species did not differ significantly in frequency of occupancy. TBL was not significantly correlated with $\mathrm{DBH}$ when all individuals and all trees were tested together $(r=-0.05, P=0.642, n=102)$ or for adults $(r=0.03, P=0.857, n=37)$ and juveniles $(r=-0.17, P=$ $0.179, n=65$ ) analyzed separately. However, individuals that occupied $S$. berteriana displayed a positive correlation between TBL and DBH $(r=0.59, P=0.004, n=22)$, while TBL was negatively correlated to DBH for individuals on $C$. schreberiana $(r=-0.63, P=$ $0.029, n=12$ ). For individuals found on $M$. bidentata, a negative correlation approached significance $(r=-0.69, P=0.085, n=7)$, but TBL of individuals found on $P$. acuminata was not significantly correlated to the DBH of the tree on which they were found $(r=0.03$, $P=0.828, n=61)$.

In the LEF, $S$. berteriana has similar characteristics (i.e., buttressed roots and large DBH) to those of trees that are selected by $H$. longicornis in northern Brazil (Dias and Machado 2007) and $P$. parvulus in Costa Rica (Hebets 2002) and may therefore provide the same putative benefits. Nevertheless, Bloch \& Weiss (2002) report that a palm, $P$. acuminata, was the tree most often occupied by 

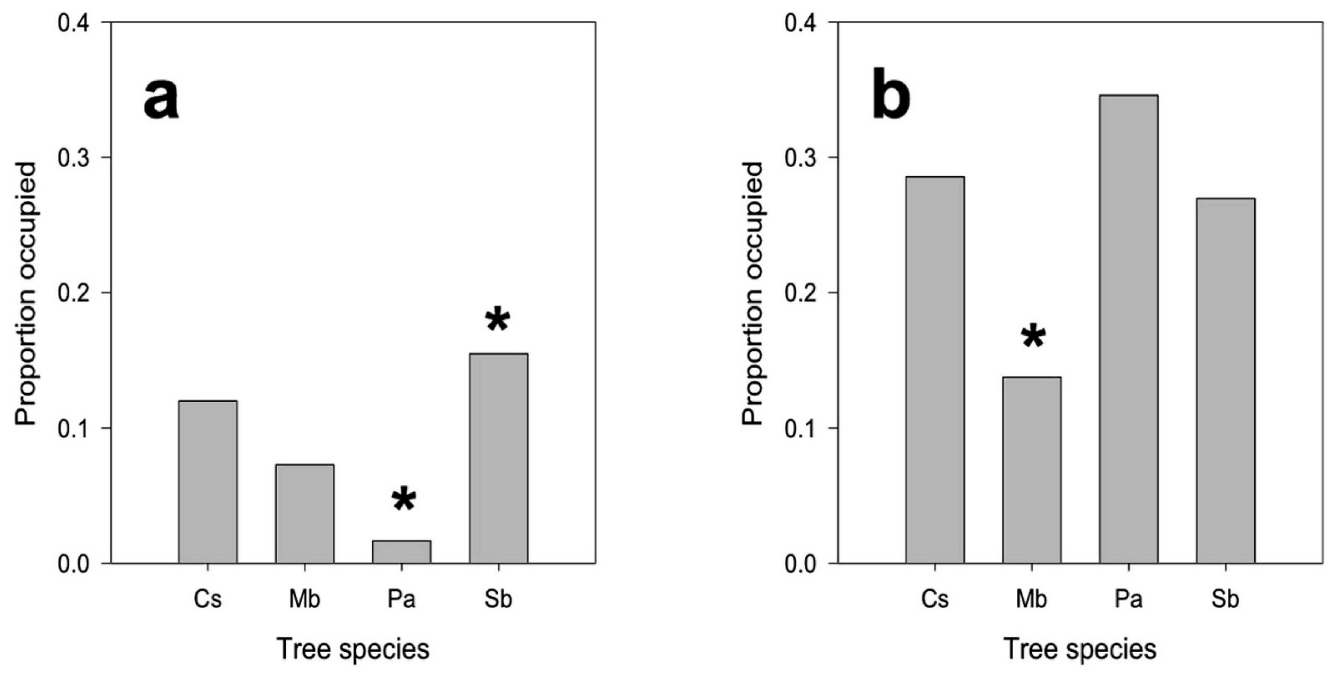

Figure 1.-Patterns of substrate use by Phrynus longipes in the Luquillo Experimental Forest. The proportion of individuals of each tree species (Cs, C. schreberiana; Mb, M. bidentata; Pa, Prestoea acuminata; Sb, Sloanea berteriana) occupied by P. longipes. a. Dry season; b. Wet season. Asterisks above bars indicate significant departures from expected occupancy based on standardized residuals of chi-square contingency tables.

amblypygids in the LEF. We reconcile the observations of Bloch \& Weiss (2002) with other studies by demonstrating changes in microhabitat use between sampling periods.

Two lines of evidence are consistent with the hypothesis that large, buttressed $S$. berteriana are preferred substrates for P. longipes in the LEF. First, $S$. berteriana was among the most frequently occupied tree species, regardless of season, especially if only relatively large trees are considered. In the dry season, $P$. longipes occupied $86 \%$ of $S$. berteriana that measured $\geq 20 \mathrm{~cm}$ and $53 \%$ that measured $\geq 10 \mathrm{~cm}$, compared to only $7.2 \%$ that measured $<10 \mathrm{~cm}$. This pattern was repeated in the wet season, as $P$. longipes occupied $75 \%$ of $S$. berteriana $\geq 20 \mathrm{~cm}, 58 \% \geq 10 \mathrm{~cm}$, but only $11 \%$ that were $<10 \mathrm{~cm}$. Second, the positive correlation between TBL of $P$. longipes and DBH of $S$. berteriana suggests that larger individuals were best able to defend a territory on large, buttressed trees.

There was a considerable shift in microhabitat use between seasons, however, with individuals avoiding $P$. acuminata in the dry season but using it as frequently as $C$. schreberiana and $S$. berteriana in the wet season. Several reasonable hypotheses may explain this pattern. Abundance or quality of prey may change seasonally, making $P$. acuminata trunks better hunting sites in the wet season than in the dry season. For example, foraging activity of $P$. longipes (Pfeiffer 1996) and insect abundance (Garrison \& Willig 1996) are greater during rainy than dry periods, suggesting that higher prey capture rates are possible during such times, even on trees that represent less suitable habitat during dry periods.

Alternatively, decreased use of $P$. acuminata in the dry season may reflect that it is unsuitable for mating, or that an ontogenetic shift in substrate selection occurred. The courtship display of many species of whip spider requires a sheltered, level area (Weygoldt 2000), such as the root surface or the caverns that form under the roots of the most frequently selected trees. The roots of $P$. acuminata generally lack such spaces. The small crevices found between $P$. acuminata roots are, however, useful as retreat sites, especially for small individuals, and may therefore provide higher quality habitat in the non-breeding season and for juveniles.

The population density of $P$. longipes was greater during the wet season than the dry season, as indicated by much higher proportional occupancy of all four tree species (Figs. 1a,b). The increase in density is probably driven by the emergence of juveniles that hatched late in the dry season or early in the wet season. As a result, competition for optimal substrates was considerably lower in the dry season than in the wet season. In the wet season, two adults were observed occupying the same tree once (on $S$. berteriana), and an adult was observed on the same tree as a juvenile in two cases (once each on $P$. acuminata and $S$. berteriana), and multiple juveniles were observed on a single tree for all species except $M$. bidentata. This suggests that food was abundant enough throughout the wet season that it did not influence habitat selection.

To maximize fitness, individuals must respond to geographic and temporal changes in resource availability either by selecting a territory that provides them with high-quality habitat in all seasons or by moving to a different, higher-quality site when resources decline. Here, we provide evidence of a shift in substrate occupation from the wet season to the dry season in a sub-tropical whip spider, $P$. longipes. Given the limitations of this study, further research is needed to determine whether our observations are consistent with a long-term pattern or if the years we sampled represent an anomaly. Nevertheless, our findings are partially consistent with other research on habitat selection by amblypygids, particularly regarding tree selection in the dry season. However, the wet-season shift to occupying what we assume are lower-quality trees indicates that although habitat characteristics such as tree size are likely to determine whether or not a tree is suitable habitat, biotic interactions such as those that occur among $P$. longipes in the wet season are likely to further influence the small-scale distribution of a species.

\section{ACKNOWLEDGMENTS}

This research was supported in part by grant number DEB-0620910 from the National Science Foundation to the Institute of Tropical Ecosystem Studies, University of Puerto Rico, and the International Institute of Tropical Forestry as part of the Long-Term Ecological Research Program in the Luquillo Experimental Forest. In particular, we thank M. Willig for the support of his sub-contract through the University of Connecticut. R. Pitt provided funding for C. Curtis through the Office of Academic Affairs at Bridgewater State University. The staff of El Verde Field Station provided valuable logistical support in Puerto Rico. I. Castro-Arellano, L. Cisneros, L. Jones, S. Kieschnick, B. Klingbeil and E. Souza provided assistance in collecting data. 


\section{LITERATURE CITED}

Bloch, C.P. \& L. Weiss. 2002. Distribution and abundance of the whipspider Phrynus longipes (Arachnida: Amblypygi) in the Luquillo Experimental Forest, Puerto Rico: response to natural and anthropogenic disturbance. Caribbean Journal of Science 38:260-262.

Carvalho, L.S., J. O Gomes, S. Neckel-Oliveira \& N.F. Lo-ManHung. 2012. Microhabitat use and intraspecific associations in the whip spider Heterophrynus longicornis (Arachnida: Amblypygi) in forest fragments formed by the Tucuruí Dam Lake, Pará, Brazil. Journal of Natural History 46:1263-1272.

Dias, S.C. \& G. Machado. 2007. Microhabitat use by the whip spider Heterophrynus longicornis (Amblypygi, Phrynidae) in Central Amazon. Journal of Arachnology 34:540-544.

Garrison, R.W. \& M.R. Willig. 1996. Arboreal invertebrates. Pp. 183-245. In The Food Web of a Tropical Rain Forest, (D.P. Reagan \& R.B. Waide, eds.). University of Chicago Press, Chicago, Illinois.

Heartsill-Scalley, T., F.N. Scatena, C. Estrada, W.H. McDowell \& A.E. Lugo. 2007. Disturbance and long-term patterns of rainfall and throughfall nutrient fluxes in a subtropical wet forest in Puerto Rico. Journal of Hydrology 333:472-485.

Hebets, E.A. 2002. Relating the unique sensory system of amblypygids to the ecology and behavior of Phrynus parvulus from Costa Rica (Arachnida, Amblypygi). Canadian Journal of Zoology 80:286-295.

Heyer, W.R. \& K.A. Berven. 1973. Species diversity of herpetofaunal samples from similar microhabitats at two tropical sites. Ecology 54:642-645.

Hobbie, J.E., S.R. Carpenter, N.B. Grim, J.R. Grosz \& T.R. Seastedt. 2003. The US long term ecological research program. BioScience $53: 21-32$.
Huey, R.B. 1991. Physiological consequences of habitat selection. American Naturalist 137:S91-S115.

McDowell, W.H. \& A. Estrada-Pinto. 1988. Rainfall at El Verde Field Station, 1964-1986. CEER-T-228. Center for Energy and Environment Research. Rio Piedras, Puerto Rico.

Pfeiffer, W.J. 1996. Arboreal arachnids. Pp. 247-271. In The Food Web of a Tropical Rain Forest. (D.P. Reagan \& R.B. Waide, eds.). University of Chicago Press, Chicago, Illinois.

Porto, T.J. \& P.E.C. Peixoto. 2013. Experimental evidence of habitat selection and territoriality in the Amazonian whip spider Heterophrynus longicornis (Arachnida, Amblypygi). Journal of Ethology 31:299-304.

Quintero, D. 1981. The amblypygid genus Phrynus in the Americas (Amblypygi, Phrynidae). Journal of Arachnology 9:117-166.

Rosenzweig, M.L. 1981. A theory of habitat selection. Ecology 62:327-335.

Scatena, F.N. \& M.C. Larsen. 1991. Physical aspects of Hurricane Hugo in Puerto Rico. Biotropica 23:317-323.

Stamps, J.A. 1991. The effect of conspecifics on habitat selection in territorial species. Behavioral Ecology and Sociobiology 28:29-36.

Thompson, J., N. Brokaw, J.K. Zimmerman, R.B. Waide, E.M. Everham III \& D.J. Lodge et al. 2002. Land use history, environment, and tree composition in a tropical forest. Ecological Applications 12:1344-1363.

Weygoldt, P. 2000. Whip spiders (Chelicerata: Amblypygi): Their biology, morphology and systematics. Apollo Books, Denmark.

Whitham, T.G. 1980. The theory of habitat selection: Examined and extended using Pemphigus aphids. American Naturalist 115:449-466.

Wolda, H. 1978. Seasonal fluctuations in rainfall, food and abundance of tropical insects. Journal of Animal Ecology 47:369-381.

Manuscript received 28 August 2013, revised January 62014 , 